\title{
Letters
}

\section{Rationality and the wish to die-a response to Clarke}

SIR

In a scholarly and thought-provoking paper, Clarke sets out to debunk the concept of "rational suicide" as nonsensical. ${ }^{1}$ His motivation in this is to undermine any support that the notion of rational suicide might give to a "categorical right to suicide". If his enterprise were successful, however, it would go far beyond the "rights issue" and would have a profound impact on all arguments raised in support of euthanasia or physician-assisted suicide.

Clarke's major thrust might be termed the argument from posthumous ignorance. $\mathrm{He}$ begins with a claim that the process of making a rational decision involves the process of "gaining all possible facts and 'imagining' all possible consequences". He goes on to say that making a rational decision "in the consideration of life or death ... would seem to be impossible". It is "impossible" because the person making the decision cannot know what death is like, and therefore cannot weigh up the risks and benefits of his or her choice to die. One just can't know what it is like to be dead - "it is essentially of an unknown quality and a matter of faith rather then rational thought".

Before examining where Clarke has gone wrong, let us leave aside the obvious impossibility of gaining all possible facts and substitute the notion of gaining all relevant facts. Further, let us gloss over the considerable difficulties in deciding what counts as relevant, by allowing that knowing what it would be like to be dead would be relevant to a decision concerning the possibility of dying. Finally, let us overlook the fact that many of us feel we have a pretty good idea what death would be like anyway.
It is quite common for people to make what we are happy to term rational decisions in situations where they do not and cannot know a fact of apparent primary relevancy. We do that the first time we make a rational decision to eat a mango. Of course, we may ask others what mangoes taste like- "sort of mangoey"-but we cannot know (in Clarke's strict sense) until we've done it ourselves. It would seem very odd to deprive any decision involving any novel activity of any possible rationality.

Clarke might respond, of course, that we are talking about something far more unknowable than the taste of mango. No one knows what death is like. "Although one can imagine that death will be like dreamless sleep or being under anaesthetic, it is an assumption or at best a guess. Nobody knows." 2 Perhaps Clarke's position is that it is not possible to make a rational decision, where one of the relevant facts is not known (in Clarke's strict sense) by anybody.

However, even this position will flounder. People make decisions, that we are happy to call rational, with exactly this limitation all the time. Nobody knows what the future will hold, but people make rational decisions that concern future possibilities. More specifically people make all sorts of rational decisions about issues that concern death. I have made a rational decision to take anti-hypertensive medication, primarily because I want to stave off death. People frequently decide to have life-saving operations for exactly the same reason. Others opt for treatments, such as bone marrow transplants, where death is a relevant possible adverse outcome. Clarke would presumably not argue that these decisions are necessarily non-rational, despite the fact that they must involve the consideration of the ultimately unknowable quality of death.

It is not necessary to gain all relevant facts to make a rational deci- sion, it is only necessary to gain those relevant facts that are reasonably obtainable and to have an understanding of the limits of one's knowledge. It is $\mathrm{OK}$ to guess, as long as you know that you are guessing. It is possible to make a rational decision about suicide.

Clarke is right to caution us to be wary of the motives of those who ask to die. A genuine request to die uninfluenced by mental illness and based on a considered weighing of the pros and cons of continued life, is a very rare beast. Rare it may be, logically impossible it is not.

\section{References}

1 Clarke DM. Autonomy, rationality and the wish to die. Fournal of Medical Ethics 1999;25:457-62.

2 See reference 1:458.

DR CHRISTOPHER JAMES RYAN MBBS FRANZCP

Consultation-Liaison Psychiatrist, University

of Sydney and Department of Psychiatry, Westmead Hospital, Westmead, NSW 2145 , Australia

\section{Hymenorrhaphy: what happens behind the gynaecologist's closed door?}

SIR

Premarital sex is socially and religiously unacceptable in some cultures, with grave consequences such as shame, rejection, divorce, or even death to "cleanse the shame". Hymenorrhaphy or hymenoplasty has emerged as a procedure which attempts to restore the ability of the hymen to bleed at intercourse on the wedding night, thus protecting women from violent reprisals.

A few articles have recently appeared in the English literature debating whether hymenoplasty is clinically indicated or ethically justified. ${ }^{12}$ If we review the English literature, we find only one article addressing the success 
of this operation in a group of 20 patients. ${ }^{1}$ The authors claim that all 20 were satisfied with the outcome and none had regrets. Long term follow up is available on only 10 patients $(50 \%)$ and they report that the procedure provided a satisfactory outcome. This single article can hardly be convincing in an era of evidence-based medicine. There is the theoretical risk of infection which might disrupt the repair, thus defeating the purpose of the operation, and there is the potential risk of bleeding with intercourse, which might be traumatic to the couple. Well controlled studies to assess success and safety are extremely difficult to perform since the procedure is illegal and religiously condemned in most of the countries where hymenoplasty is performed, and neither the patients nor the physicians are willing to be involved in medicolegal or social conflicts. Most of the time, the medical records of such procedures are destroyed and follow up of these patients risks exposing the secret they are trying so desperately to hide.

The procedure is financially rewarding to the physicians and taxing for women. The cost of such a simple procedure might become very high, depending on the physicians' whims and their estimation of the financial resources of the patients. Physicians might attempt such an operation for the first time for financial gratification even if they have no notion about the operation, since it is not taught in medical schools and is not found in any textbook of gynaecological surgery.

There are unperceived social and psychological risks attached to performing the operation on request. Awkward situations might arise and multiple questions should be addressed before considering the procedure as acceptable ethically, morally, or legally. What is the limit on the number of hymenoplasties women are justified in asking for? A few men are presenting to our clinics requesting a gynaecological examination of their prospective wives before marriage to ensure that such an operation has not been done. Such operations will make all women suspects in the eyes of their men even if they are conforming to cultural standards and moral values. The psychological and social implications of a forced examination on the marriage as a whole are tremendous. By performing such procedures, physicians will be protecting a few women only through harming the majority. In addition, the physician checking for virginity is usually in a predicament when a repair is discovered. Even if the doctor thinks that he or she has a duty towards the patient alone, the responsibility for the morality of the patient's relationship with her husband cannot be denied since the proposed operation is intimately concerned with that relationship. Although the operation is done for women, yet the sole purpose is to deceive men. Respect for women's autonomy directly clashes with men's autonomy.

Finally, surgical repair of the hymen reflects social injustice and hypocrisy since it confirms social inequality. It might deter sexual abuse victims from disclosing sexual violence and questioning the offender.

In conclusion, hymenoplasty is a simple gynaecological procedure that creates a multitude of moral, ethical, social and religious controversies. Practising gynaecologists should be aware and familiar with these implications before taking the decision for or against performing it.

\section{References}

1 Logmans A, Verhoeff A, Bol Raap R, Creighton F, Van Lent $M$. Ethical dilemma: should doctors reconstruct the vaginal introitus of adolescent girls to mimic the virginal state? British Medical fournal 1998;346:459-62.

2 Kandela P. Egypt's trade in hymen

repair [letter]. Lancet 1996;347:1615.

IHAB USTA, MD

Department of Obstetrics and Gynecology, American University of Beirut Medical Center, Beirut, Lebanon

\section{On an alleged problem for voluntary euthanasia}

SIR

Dr Campbell presents proponents of euthanasia with a dilemma. ${ }^{1}$ Only voluntary euthanasia is permissible; involuntary euthanasia is always impermissible. The question of allowing euthanasia arises most frequently when patients are terminally ill and experiencing great pain. But in these cases, he argues, if patients request euthanasia, their decision "is not freely chosen but is compelled by the pain". It is easy to exaggerate the problem here; patients may have periods when they are pain-free and affirm repeatedly their desire that death be hastened. Putting this aside, however, what should we conclude if euthanasia performed on patients who are suffering greatly is not voluntary?
Dr Campbell concludes: "If the request to end one's life is not made freely, then it is doubtful that such requests ought to be followed". ${ }^{2}$ An advance directive will not help, we are told, because the individual may have changed his or her mind. Dr Flew sensibly replies that the best we can do in these cases is to have detailed advance directives, an example of which he provides. ${ }^{3}$ Society could even add a safeguard to this: require individuals to "renew" these documents periodically-say, every two years.

This practical reply, however, leaves unexposed two questionable aspects of Dr Campbell's argument. The first is that his position presents us with a false dilemma. Dr Campbell says that in cases where patients are suffering "euthanasia turns out to be involuntary" and therefore impermissible. And involuntary euthanasia is characterised as taking the life of another human being "against his or her will". Most will agree that involuntary euthanasia, so characterised, should not be allowed. But it does not follow from the fact that euthanasia is not voluntary that it is involuntary. There is another category, nonvoluntary euthanasia; it involves taking the life of another human being without his or her consent or request. Involuntary euthanasia is a special case of nonvoluntary; but nonvoluntary also includes cases in which patients are unable or unwilling either to protest or to give free and informed consent. This is pertinent because while most people will readily agree that involuntary euthanasia is wrong, there is less consensus about those cases of nonvoluntary euthanasia that are not against the patient's wishes. And these are precisely the cases with which Dr Campbell is concerned.

The second problematic aspect of Dr Campbell's argument concerns the specific recommendation that he believes follows from the fact that a request for euthanasia is not known to be voluntary. He maintains that in such cases the request should not be followed. Apparently it is permissible to act on the request only if it is known to be voluntary. But this is a very demanding standard, and one that is not at all reasonable in most areas of medicine. If a patient in great pain presents in the emergency room of a hospital and consents to recommended surgery, we do not hesitate to perform the procedure because the pain renders the consent not voluntary. It is question-begging to retort 
that this case is different from euthanasia because the surgery is obviously rational and in the patient's best interests. For as Dr Campbell rightly concedes, if a patient's pain is irremediable and can be ended only by hastening death, then it may well be rational for that patient to choose to end his or her life.

In many contexts of medicine, doubts can be raised about whether a patient's consent is informed or fully voluntary. The best that fallible humans can do is to look for additional evidence of what the patient wants. That we do this demonstrates our commitment to the precepts dubbed "the advance directive principle" and "the substituted judgment standard". ${ }^{4}$ We even appeal to these precepts when patients clearly lack decision making capacity. Evidence does not always produce certainty, but we do not demand certainty even when the results will be life-altering or irreversible. Were we to demand certainty, in many cases we would not be authorised to act. In the cases discussed by Dr Campbell, refusal to act in the absence of certainty makes it more likely that we will fail to honour these patients' wishes; in addition, we will deny them relief from their agony.

\section{References}

1 Campbell N. A problem for the idea of voluntary euthanasia. Fournal of Medical Ethics 1999;25:242-

2 See reference 1: 243.

3 Flew A. Advance directives are the solution to Dr Campbell's problem for voluntary euthanasia. Fournal of Medical Ethics 1999;25:245-6.

4 Buchanan AE, Brock DW. Deciding for others: the ethics of surrogate decision others: the ethics of surrogate decision
making. Cambridge: Cambridge University Press, 1989.

TERRANCE MCCONNELL, PHD Department of Philosophy University of North Carolina at Greensboro Greensboro, NC 27402-6170, USA E-mail: tcmcconn@uncg.edu 